\title{
A Stylo- Pragmatic Appraisal of Lawal's Communicative Model Theory
}

\author{
Acheoah John Emike (PhD) \& Margaret Nonyerem Agu \\ 1. Department of European Languages, Federal University Birnin-Kebbi, Kebbi State, Nigeria. Email: \\ actualemike@gmail.com \\ 2. Department of English, Ibrahim Badamasi Babangida University, Lapai, Niger State, Nigeria.
}

\begin{abstract}
This paper is essentially an appraisal of Lawal's Communicative Model Theory within the purview of stylistics and pragmatics. Any investigation of the stylistic and pragmatic factors that motivate language use is inevitably immersed in language users' supremacy over the normative properties of language. One of the factors that promoted scholarly interest in pragmatics is the possibility that significant functional explanations can be given for linguistic facts. Like any study in pragmatics, research in stylistics investigates contextual factors that inform language use; in this regard, the meaning of an utterance - not its grammaticalness - is the major concern. This paper hinges on The Pragma-crafting Theory as a theoretical framework and concludes that although the Communicative Model Theory is bedeviled by its inability to explain certain dimensions of language use, it captures the contextual underpinnings of language use.
\end{abstract}

\section{Keywords : Pragmatics, stylistics, Communicative Model Theory, Pragma-crafting Theory, appraisal}

\section{Introduction}

This paper investigates the potency of the Communicative Model Theory in the explanation of language use in spoken or written texts. It is from the functional perspective of language use, that linguistic structures can be explained by reference to non-linguistic (extra-linguistic) properties. The Communicative Model Theory is a framework for the explanation of language use across genres. Fundamentally, linguistic theories are evolved to enrich the literature on a wide range of theoretical issues. To ascertain the significance of the Communicative Model Theory in terms of advancing knowledge in the literature, this study examines the strengths and weaknesses of the theory - an integrative, discursive appraisal.

\section{Literature Review}

In this section of the paper, we discuss the Communicative Model Theory, stylistics and pragmatics.

\subsection{The Communicative Model Theory}

Lawal [1] posits that the Communicative Model theory is eclectic in nature because it is the totality of the submissions of predating stylistic theories. The theory explains the interaction between "message" and "medium" through socio-linguistic and rhetorical devices. Elements in the theory include: SPEAKER OR WRITER MESSAGE (i.e.) writer's or speaker's expression in the form of ideas, beliefs, knowledge, feelings and attitudes, etc. on the one hand, or listener's or reader's impression decoded in the form of ideas, beliefs, knowledge, feelings, etc.; MEDIUM i.e. writer's or speaker's expression encoded in the form of: (i) A rhetorical mode (the primary stylistic device which incorporates linguistic norms and directs pragmatic interpretation of textual properties); (ii) Linguistic 'norms', constants, variants, and deviants.

\subsection{Stylistics}

Stylistics is the study of style. Texts are viewed as "language in action". Style refers to all the factors that determine language use. Banjo [2] defines stylistics as "the exhaustive study of the role of language in literary works". Stylistics is a meeting point between literary and non-literary study of texts. Stylistic features of a text are products of the manipulation of the linguistic repertoire at the disposal of the writer. Leech and Short [3] posit that "style can be applied to both spoken and written, both literary and non-literary varieties of language, but by tradition, it is particularly associated with written literary texts." Like the discourse analyst, the stylistic analyst focuses not just on the linguistic aspects of language use, but also on the external factors that impinge on the meanings of utterances. Different theories abound within the domain of stylistics for standard description of "the process of meaning", when language is used in creative or non-creative texts. Stylistic analysis is viewed as a systematic, rigorous and result-driven endeavour. Various contextual nuances inform language use: social and physical circumstances, identities, attitudes, abilities and beliefs of participants and relations holding or supposed to be holding between participants. The thrust of research in stylistics is the analysis and description of the linguistic and extra-linguistic features of texts. Stylistics captures how users of language recreate or reinvent language as evident in the major literary genres: drama, poetry and prose. 


\subsection{Pragmatics}

The term "pragmatics" evolves from the Greek word pragma which means "deed" or "action". Contemporary use of the term is attributed to the philosopher, Charles Morris (cited in Acheoah [4]), who attempted to outline the general shape of a science of signs (or semiotics). Within semiotics, he distinguished three distinct branches of inquiry: syntactics (or syntax), semantics and pragmatics. Within the scope of analytical philosophy, pragmatics was subject to a successive narrowing of scope. Pragmatics emerged as a reaction against formalist approach to language study - an approach which deprived man of the most outstanding of his ability - the ability to negotiate a meaning to the world instead of extracting a meaning that is already there. The emergence of pragmatics replaced "linguistic competence" with "communicative competence". It is from the functional perspective of language use, which pragmatics is concerned with, that linguistic structures can be explained by reference to non-linguistic (extra-linguistic) properties.

The goal of pragmatics is to systematically account for the dynamics of human communication in relation to meaning. David

A. Brenders [5] posits that "One of the central issues involved in any systematic analysis of communication is the role of "meaning" in conversation. One general trend in such analyses has been to regard meaning as the products of social action. While this approach promotes the sensible idea that communication is the product of social actors in context rather than the mere adherence to language rules, this position has tended to blur the distinction between semantic and pragmatic meaning, and illocutionary versus perlocutionary acts. As a result, slogans such as "Words don't mean, people mean," are used widely, while research proceeds with little or no discussion of whether this approach yields consistent and sensible analyses of meaning in communication." Linguistic research that investigates contextual factors in language use is essentially of pragmatic relevance. Pragmatics is no doubt, a fascinating field of linguistic research. It is widely concerned with how language users process language in communication situations. The early scholars of this field of linguistic inquiry - just as the contemporary scholars of the field are referred to as "language philosophers". Pragmatics investigates: who uses a piece of language; "where"; "how"; "when"; and "why" that piece of language is used.

\section{Theoretical Anchorage 3.1 The Pragma-crafting Theory}

Within the framework of the Pragma-crafting Theory, "P-crafting" is a super-ordinate pragmatic act which produces linguistic and extra-linguistic elements of communication.
At different stages of a communicative event, the inferential process reveals that there are candidates for meaning: Geoimplicatures (GIs), Linguistic Implicatures (LIs), Behavioural Implicatures (BIs), Contextual Presuppositions (CPs), Pragmadeviants (PDs), Object Referred

(OR) and Operative Language (OL). We shall explain a few of these concepts that are crucial to this study. See Acheoah [6] for the diagram and elaborate perspectives on the theory. However, as we proceed with the analysis, other relevant concepts in the theory will be explored, thus making their meanings clear.

i. Setting: This is the physical context of the communicative event in both immediate and remote (referential) sense.

ii. Theme: This is the message conveyed in/by Text.

iii. Sociolinguistic Variables: They are meanings conveyed by age, cultural background, social status, race, gender, relationships, etc.

iv. Psychological Acts: These are the different emotions expressed through linguistic and extra-linguistic acts.

v.Inference: Inference-making has to do with making logical deductions from available linguistic and extra-linguistic components of Text.

vi. Indexicals: They are grammatical categories that have the potential to establish the relationship between language and context.

vii.Shared Contextual Knowledge: This refers to pieces of information available to participants of the on-going discourse for effective communication.

viii. Emergent Context: It is any emergent situation in an on-going communicative event. It redirects the performance and interpretation of subsequent linguistic, extra-linguistic and psychological acts. An emergent context becomes Shared Knowledge of Emergent Context (SKEC) when it translates into common knowledge of the participants of discourse.

ix.Geoimplicature: Coined from "geographical" and "implicature", the term "Geoimplicature" refers to verbal and non-verbal practices that are restricted to people (race/speech communities) and geographical (physical) boundary. They are not universal human behaviour.

x.Linguistic Implicature: It is any meaning implied through language.

xi.Behavioural Implicature: It is any meaning conveyed by extra-linguistic and psychological acts.

xii.Contextual Presupposition: This is a product of shared contextual knowledge.

xiii.Background Assumptions: In an on-going communication, participants deduce meanings from verbal and non-verbal data. Such meanings are referred to as Background Assumptions (BAs). 
xiv.Pragmadeviants: They are deviant expressions used by participants of discourse, as illocutionary strategies.

xv.Interactive Participant: This is an interlocutory participant who performs linguistic, extra-linguistic and psychological acts, as communicative contributions that do not only impinge on the interpretive process, but also determine or generate sequel (perlocutionary act).

xvi.Non-interactive Participant: A non-interactive participant does not participate in an on-going communicative event, but is intentionally or accidentally present in the physical context.

\section{A Stylo-pragmatic Appraisal of Lawal's Communicative Model Theory}

In this section of the paper, we examine some strengths and weaknesses of the Communicative Model Theory.

\subsection{Strengths of Communicative Model Theory}

The Communicative Model theory provides insights on speaker-meaning; it presents "medium" of communication as speakers' source of rhetorical devices. This is vital in pragmatics because communication is about the best way a speaker conveys information and the easiest way such pieces of information is retrieved by the addressee. Usually, speakers desire to produce some effects on their addressees. Therefore, such speakers explore communication skills during interactions. Commenting on the effects of verbal and non-verbal communication strategies, Austin [7] submits that "saying something will often, or even normally, produce certain consequential effects upon the feelings, thoughts, or actions of the audience, or of the speaker, or of other persons; and it may be done with the design, intention or purpose of producing them ... we shall call the performance of an act of this kind the performance of perlocutionary act or perlocution ... It is characteristic of perlocutionary acts that the response achieved or the sequel can be achieved by additional or entirely by non-locutionary means: thus intimidation may be achieved by waving a stick or pointing a gun." Speaker-meaning is successfully conveyed when substantial shared knowledge operates between the speaker and his/her hearer. This view aligns with Bruno G. Bara [8] who notes that "Communication is essentially a cooperative activity between two or more people in which the meanings of each transaction are constructed by all those actors together engaged in the shared task of reciprocally attending to the other communicants' words1." It is the task of the decoder of an utterance to work out its meaning in context. Stranson (cited in Leech [3]) posits that "understanding is decoding or calculating all that might reasonably have been meant by the speaker of the utterances." Within the framework of the Communicative Model Theory, it is obvious that contextual variables are clearly linked in the process of encoding or decoding utterances.
The link between context and language use is depicted in the Communicative Model Theory given the fact that the ideas, beliefs and feelings of participants impinge on how they deploy the "message" component of the theory in naturally-occurring cases of language use. For example, Lawal [1] submits that "a rhetorical mode" is the primary stylistic device which incorporates linguistic norms and directs pragmatic interpretation of utterances. Apart from being grammatically correct, utterances should also be assessed by the extent to which they are germane to the context, by the way in which they are deployed as actions having perlocutionary effects on addressees. Speech act is core to pragmatics because it reveals the force of utterances in varied contexts and situations: requests, commands, assertions, information, etc.

Levinson [9] rightly notes that "understanding an utterance involves the making of inferences that are assumed or what has been said before. Lyons [10] lists the following as features that are culturally and linguistically relevant to the production and interpretation of utterances: (i) knowledge of "role" and "status" (where role covers both role in speech event as speakers or addressees, and social role, and status covers notions of relative social standing), (ii) knowledge of spatial and temporal location, (iii) knowledge of formality level, (iv) knowledge of the medium (roughly the code or style appropriate to a channel, like the distinction between written and spoken varieties of a language, (v) knowledge of appropriate subject matter, (vi) knowledge of appropriate province (or domain determining the register of a language). Ochs, in an extended discussion of the notion, notes: "The scope of context is not easy to define ... one must consider the social and psychological world in which the language user operates at any given time. Scholars note that the appropriateness of an utterance in context is essentially pragmatic presupposition."

The Communicative Model Theory reveals something very significant: the fact that remote and immediate background knowledge are crucial in human communication. This fact directs the contributions and attitudes (actions) of participants of discourse. According to Carassa and Colombetti [11] "collective actions involve a normative relationship between agents." Essentially, the collective actions of participants demonstrate the presuppositions that underpin the given communicative event. The literature of pragmatics contend that presupposition is tied to the performance and interpretation of speech acts. Wodak [12] submits that "the concept of presupposition is central to linguistics. The analysis of presuppositions within speech act theory, which began with John Austin (1961), makes it possible to make explicit the implicit assumptions and intertextual relations that underlie text-production". 
Obviously, the Communicative Model Theory does not ignore the relevance of context in communication. Noting that contextual factors underpin communication, Adeyemi [13] submits that "there are two kinds of context recognized in language study: verbal and situational contexts. The verbal context refers to the company which a linguistic item keeps in connected speech (not words in isolation). This reduces the instances of syntactic or lexical ambiguity that may be found if items are considered separately. Unlike the verbal context (which is within the purview of linguistics) the situational context falls mainly within the purview of pragmatics. The situational is divided into the context of culture and immediate context. The context of culture (Firth 1962) specifies the conventional or socio-cultural rules of behavior which participants must share before they can communicate successfully with each other.

Some of these conventional rules may be universal ... These ideas enlighten us about how participants establish and maintain socialization in communicative interaction. A child normally learns the values and pre-occupations of its culture largely by learning the language." So long as speakers do not always use literal language, context remains instrumental in decoding speaker-meaning. Searle [14] avers that "indirect speech act belongs to a higher level of pragmatic meaning. The meaning in indirect speech act is not explicit, and it requires pragmatic elements such as context, mutual contextual beliefs (MCBs) and world knowledge to bring out its meaning". The Pragma-crafting Theory captures the various contextual nuances that anchor the production and interpretation of utterances: Geoimplicatures (GIs), Linguistic Implicatures (LIs), Behavioural Implicatures (BIs), Contextual Presuppositions (CPs), Pragmadeviants (PDs), Object Referred (OR) and Operative Language (OL).

\subsection{Weaknesses of the Communicative Model Theory}

The Communicative Model Theory does not explicate speech act which is the core of meaning beyond the sentence. This is a major flaw of the theory because natural communication is inevitably immersed in speech acts (doing things with utterances). According to Jacob Mey [15], "speech acts are produced not in the solitary philosopher's thinking, but in actual situations of language use, by people having something 'in mind'. Such a production naturally presupposes a 'producer' and a 'consumer', human agents, whose intentions are relevant and indispensable to the correct understanding and description of their utterances, quite contrary to the constructed, non-use-oriented examples of most grammarians and philosophers."

The fact that speech acts are often intentionally performed, makes them crucial in communication; their intentional characteristics is also a basis for their classification.
Jacob Mey [15] also opines that "as to the question of intentions, any discussion of intentionality should be aware of the relationships that exist among the individuals to whom the intentions are ascribed, and of the ways they perceive the others as intentional beings, in a greater, societal context. It is not primarily what I say, or intends to say, that determines my speech act, but the way it fits into the entire pattern of acting as a social being that is typical for my culture. Even though speech is a constitutive component of human individual and social life (as is language in general), it is still part of a larger context, of an even more encompassing activity. In the final analysis, we will have to ask ourselves how speech acts relate to our human activity as a whole: thinking 'globally' while acting 'locally', as the saying goes. It is for this ecological view of human acting, to which the societal and global environment provides the adequate (necessary and sufficient backdrop that I have devised the term "pragmatic act' ....)."

The Communication Model Theory does not enrich the literature as far as implicature and presupposition are concerned. The Pragma-crafting theory evolves critical perspectives on presupposition and implicature because they are crucial components in inference-making. For example, novel categories of implicature (Linguistic Implicatures (LIs), Behavioural Implicatures (BIs)) and presupposition (Contextual Presuppositions (CPs)) are mentioned in the theory. Acheaoh [6] submits that "Linguistic Implicatures (LIs) are meanings implied through language while Behavioural Implicatures (BIs) are meanings implied through extra-linguistic and psychological acts. Contextual presuppositions (CPs) are products of shared contextual knowledge (SCK); in a specific (micro-context) discourse participants deduce meanings from verbal and non-verbal data limited to the participants themselves. The meanings deduced are treated as background assumptions (BAs) which direct interlocutory roles."

Noting that implicature is crucial in the interpretation of utterances, Levinson [9] asserts that "one of the great attractions of the notion of conventional implicature is that it promises to simplify semantics substantially. For example, the proliferation of senses of lexical items can be avoided by noting that implicatures often account for different interpretations of the same item in different contexts3." The Communicative Model Theory will be more text-operative if it investigates issues revolving around implicatures and presuppositions. Most contemporary pragmatic theories are neo-Gricean because of Grice's phenomenal theorizing on implicature. 
Like implicatures, presuppositions facilitate the use of reference and inference in discourse. This is because implicatures encapsulate socially realistic phenomena (worlds-spoken-of). In this sense, Frege [16], cited in Levinson [9] is instructive:"Concerns with presuppositions originate with debates in philosophy, specifically debates about the nature of reference and referring expressions. Such problems are at the heart of logical theory and arise from consideration of how referring expressions in natural language should be translated into the restricted logical language. The first philosopher in recent time to wrestle with such problems was Frege, the architect of modern logic. For instance he said: If anything is asserted there is always an obvious presupposition that the simple or compound proper names used have a reference. If one therefore asserts "Kepler died in misery", there is a presupposition that the name "Kepler" designates something.

The Communicative Model Theory does not mention the functionality of non-verbal means of communication. This situation does not place the theory in a good stead in terms of accounting for the switch from verbal to non-verbal communication by participants, for pragmatic reasons. Scholars acknowledge that non-verbal (or paralinguistic components of communication amplify the actual use of language (verbal communication). Austin [7] interestingly points out that "it is characteristic of perlocutionary act that the response achieved or the sequel can be achieved additionally or entirely by non-locutionary means: thus intimidation may be achieved by waving a stick or pointing a gun.

Note that responses and sequels can be achieved by both conventional and non-conventional means. Strictly speaking, there cannot be an illocutionary act unless means employed are conventional, and so the means of achieving it non-verbally must be conventional. For example, if I give something to someone by swinging a stick, then swinging my stick is a warning: he would know very well what I meant: it may seem an unmistakable threatening gesture. But the fact remains that many illocutionary acts cannot be performed except by saying something." The disregard for non-verbal means of communication mainly presents the Communicative Model Theory as a theory of speaking rather than a comprehensive theory on human communication - incorporating non-verbal communication.

Numerous fascinating perspectives abound in the literature of pragmatics on the instrumentality of non-verbal means of communication in discourse. One of such perspectives is that of Christiana Ogidi-Andrew [17], who avers that "specifically, non-verbal communication involves sending and receiving messages in different ways.
It includes intentional/unintentional non-use of verbal codes and a variety of behaviours, touch, glance, eye contact, facial expression, posture, dress, gesture, intonation, and so on. Non-verbal stimuli in a communication basically comprise non-verbal messages produced by the body and that produced by the broad setting of time, silence, space and so on." Within the framework of The Pragma-crafting Theory, "semiotic particulars" and "sociolinguistic variables" (meanings conveyed by age, cultural background, social status, race, gender and relationships capture non-verbal means of communication. Semiotic particulars include non-lyrical music, laughter, sounds, etc.

\section{Discussion}

This paper examines Lawal's Communicative Model Theory with a view to unfolding its strengths and weaknesses. Indeed, the instrumentality of the theory in the analysis of language use is impressive. However, its shortcomings are worrisome, particularly because of the dynamic nature of human communication. In pragmatics, we study the gamut of factors that influence the choice of verbal and non-verbal means of communication: sounds, construction and words. The Communication Theory shows that when human beings interact, they essentially articulate speaking strategies/skills in contexts; that is, using language to convey politeness, intimacy, solidarity, etc. To some extent, the ability to communicate messages is inherent in man (generic). Bruno G. Bara [8] submits that "human beings, unique among animals, possess a basic communicative competence that sustains both the linguistic and the extralinguistic way of expressing it."

The Communicative Model Theory is integrative to a reasonable extent because it is interdisciplinary; it is immersed in sociology, history and religion. This stance makes the theory align with the submission of Wodak [12] who asserts that "an integrative pragmatic and discourse-analytic approach has to be further complemented with a range of other linguistic theoretical concepts as well as with theories from neighbouring disciplines. Such theoretical framework would rather be necessary to be able to choose and justify the relevant categories for the analysis itself'. There is a sense in which the Communicative Model Theory implies that language use is psychological and environmental; mindsets and worldviews of speech communities influence not only the sequel of utterances, but also the encoding and decoding of such utterances. This view corroborates Ming-Chung Yu [18] who notes that "Searle (1975), supporting Austin's (1962) claim that speech acts are semantic universals and hence not culture-bound, maintains that across languages and cultures there are general norms for realizing speech acts and conducting politeness behaviour, and that while the forms embodying these norms may vary from one language to another, the cross-cultural differences are not that important." 
In a similar vein, Carnap (1956, cited in Levinson [9]) contends that "there was room for a pure pragmatics which would be concerned with concepts like "belief" "utterance" and "intention" and their logical interrelation." In using an Operative Language to convey meaning in context, participants of discourse do not just deploy their knowledge or mastery of the Operative Language (linguistic competence); they also deploy communicative competence, given the fact that unlike grammar, pragmatics is principle-driven. Levinson [9] instructively opines that "the term 'pragmatics' covers both context-dependent aspects of language structure and principles by language usage and understanding that have nothing or little to do with linguistic structure". Indeed, linguistic structure is not incidental; it is purposeful. Levinson [9] submits that "pragmatic principles of language usage can be shown systematically to "read into" utterance more than they conventionally or literally mean. This hope makes it clear that one of the reasons for the development of pragmatics (or interest in pragmatics) is the possibility that pragmatics can effect a radical simplification of semantics. Another reason for growing interest is growing realization that there is a very substantial gap between current linguistic theories of language and accounts of linguistic communication."

\section{Conclusion}

Ayodabo [21] submits that "the goal of pragmatics is to explain how a listener can succeed in retrieving some interpretation intended by the speaker from an uttered sequence of words ..." However, it is the contextual nuances of human communication that facilitate the interpretation of utterances. The Communicative Model Theory accentuates the fact that in communicative situations, interlocutors use their understanding of the linguistic and extra-linguistic facilitators of the process of encoding utterances and decoding same. Adeyemi [13] submits that "schemata" is the plural word for "Schema". It refers to either (the totality of items of knowledge in the brain) or (the totality of items activated in relation to a particular topic in a communicative process). Each schema denotes items of knowledge that are associated with an object, person, event, action, place, etc." On the whole, the Communicative Model Theory - as examined in this paper - reveals that a speaker succeeds in communication when his/her utterance is easily processed by the hearer; indeed, human interaction is essentially immersed in the communication and interpretation of messages.

\section{Notes}

1. However, Bruno. G. Bara [10] notes that "the aims of the actors engaged in an interaction may differ, but to be able to say that communication has taken place successfully, all the participants must share a set of mental states."

2. Levinson [9] adds that "there are a number of examples of the fact that pragmatic constraints on syntax can be attributed to conversational implicature."

3. An implicature is not overtly stated; its meaning is to be skillfully worked out by exploring contextual presupposition.

\section{REFERENCES}

1. Lawal, A. (2012). Aspects of a stylistic theory and the implications for practical criticism. In Adebayo Lawal (ed.), Stylistics in Theory and Practice. Ilorin: Applied Linguistics Study Group (ALSG), University of Ilorin, p. 38.

2. Banjo, A. (1982). The linguistic factor in African literature: A keynote address. Paper presented at the 7th Ibadan African Literature Conference, University of Ibadan.

3. Leech, G. \& Short, M. H. (1981). Style in fiction: an introduction to English fictional prose. London: Longman Group Limited, p. 3.

4. Acheoah, J. E. (2011). A pragmatic analysis of Ayi Kwei Armah's The beautyful ones are not yet born and Ola Rotimi's Hopes of the living dead. Ph.D. dissertation. Zaria: Ahmadu Bello University.

5. David, A. B. (1987). Fallacies in the coordinated management of meaning: a philosophy of language critique of the heirachical organaization of coherent conversation and related theory. Quarterly Journal of Speech, (73): 329-348.

6. Acheoah, J. E. (2015). The Pragma-crafting theory: A proposed theoretical framework for pragmatic analysis. American Research Journal of English and Literature 1(2): 21-32.

7. Austin, J. L. (1962). How to do things with words. Cambridge: Harvard University Press, p. 119.

8. Bara, B. G. (2010). Cognitive pragmatics: the mental processes of communication. Cambridge, MA: MIT Press. Translated by J. Douthwaite. 
9. Levinson, S. (1983). Pragmatics. Cambridge, Cambridge University Press, pp. 37, 162.

10. Lyons, J., (1977). Semantics 1. Cambridge: Cambridge University Press, p. 574.

11. Carassa, A. \& Macro, C. (2012). On normative cognition and why it matters for cognitive pragmatics. Intercultural Pragmatics, 9(2), 271-280.

12. Wodak, R. (2007). Pragmatics and critical discourse analysis: a cross-disciplinary inquiry. Pragmatics and Cognition, 15(1): 203-225.

13. Adeyemi, O. B. (2000). Studies in English language. Ibadan: Enicrownfit Publishers, p. 71.

14. Searle, J. (1979). Expression and meaning. Cambridge: Cambridge University Press.

15. Mey, J. (2001). An introduction to pragmatics. Oxford: Blackwell Publishing, pp. 93-95.
16. Frege, G. (1997). The Frege Reader. Oxford; UK; Cambridge, Mass.: Blackwell Publishing.

17. Christine, I. O. (2017). English and its offspring: an exploration of socio-historical trajectories, alternative perspectives, and contemporary language practices in a postcolonial context. JESAN, 19(2): 2.

18. Min-Chung, Y. (2005). Sociolinguistic competence in the complimenting act of native Chinese and American English speakers: A mirror of cultural value. Language and Speech, 48(1): 91-119.

19. Gilbert, L. (2004). On the status of linguistics with particular regard to typology. The Linguistic Review, (21): 389-411.

20. Lenny, C. (2009). The rhetorical relations approach to indirect speech acts: problems and prospects. Pragmatics \& Cognition, 17(1): 43-76.

21. Ayodabo, J. (2013). Linguistic and sociolinguistic situation in Nigeria. Ilorin: Haytee Press, p. 122.

Citation: Acheoah John Emike (PhD) \& Margaret Nonyerem Agu., “A Stylo- Pragmatic Appraisal of Lawal's Communicative Model Theory". American Research Journal of English and Literature, Volume 7, Issue No. 1, 2021, pp. 1-7.

Copyright (C) 2021 Acheoah John Emike (PhD) \& Margaret Nonyerem Agu, This is an open access article distributed under the Creative Commons Attribution License, which permits unrestricted use, distribution, and reproduction in any medium, provided the original work is properly cited. 